\title{
A Simplified Model Applied to the Barite Sag and Fluid Flow in Drilling Muds: Simulation and Experimental Results
}

\author{
José Messias Ribeiro Jr. ${ }^{1}$, Felipe Moreira Eler ${ }^{1}$, André Leibson Martins ${ }^{2}$, Cláudia Miriam Scheid ${ }^{3}$, \\ Luís Américo Calçada ${ }^{3}$ and Luiz Augusto da Cruz Meleiro ${ }^{3 *}$ \\ ${ }^{1}$ Graduate Program in Chemical Engineering, Federal Rural University of Rio de Janeiro, Rodovia BR 465, km 7, Seropédica, RJ 23890-000 - Brazil \\ 2 Research \& Development Center Leopoldo Américo Miguez de Mello (CENPES), Brazilian Petroleum Corporation (PETROBRAS), \\ Avenida Horácio Macedo 950, 21.941 1-915, Rio de Janeiro, RJ - Brazil \\ ${ }^{3}$ Department of Chemical Engineering, Federal Rural University of Rio de Janeiro, Rodovia BR 465, km 7, Seropédica, \\ RJ 23890-000 - Brazil \\ e-mail: meleiro@ufrri.br \\ * Corresponding author
}

\begin{abstract}
In this work, a study on the modeling of sedimentation and transport of barite particles in drilling fluids was developed. The goal of this study was to evaluate the feasibility of using a simplified two-phase model based on conservation equations to describe the sedimentation of particulate material in drilling fluids. The model was evaluated in three different case studies, where the transport and the sedimentation of solid particles in a carrying fluid were simulated. The simulation results included a two-dimensional flow of liquid in the absence of particles; the axial flow of fluid and particles to investigate the existence of the slip velocity; and the one-dimensional particle settling in drilling fluids. The resulting model used to predict the barite sag is based on the conservation equations and uses the Eulerian approach to take into account the two-phase flow. The model was able to predict the barite sedimentation as well as the formation and properties of the bed of particles. Moreover, the proposed model can be used to evaluate the influence of the particle size, the liquid viscosity, and the solids concentration on the sedimentation process of particles in drilling fluids. Experimental work was also conducted in order to estimate the parameters of the proposed model related to the solid-solid force interaction due to solid particles, and the contribution of the pressure gradient. The results were analyzed by using the one-way ANOVA test for a 95\% confidence level, and showed significant reproducibility. Therefore, despite to the simplicity of the proposed model, it could be used as a first approach to the modeling of the barite sag in drilling fluids.
\end{abstract}

\section{LIST OF SYMBOLS}

A Parameter of a quadratic form correlation

$b$

$c$

$C_{\mathrm{D}}$ Empirical parameter for pressure gradient of the barite settling

Solids volumetric concentration

Drag coefficient
$D \quad$ Diameter of the simulated system

$d \quad$ Particle diameter

$f_{11} \quad$ Liquid-liquid force per unit volume

$f_{\mathrm{s} 1} \quad$ Solid-liquid force per unit volume

$f_{\text {ls }} \quad$ Liquid-solid force per unit volume

$f_{\text {ss }} \quad$ Solid-solid force per unit volume

$f_{\text {lw }} \quad$ Liquid-wall force per unit volume 


$\begin{array}{ll}f_{\mathrm{sw}} & \text { Solid-wall force per unit volume } \\ g & \text { Acceleration of gravity } \\ L & \text { Length of the simulated system } \\ P & \text { Pressure } \\ R e & \text { Reynolds number } \\ v_{1} & \text { Velocity of liquid } \\ v_{\mathrm{s}} & \text { Velocity of solids }\end{array}$

\section{GREEK LETTERS}

$\begin{array}{ll}\theta & \text { Inclination angle } \\ \mu_{1} & \text { Viscosity } \\ \rho_{\mathrm{s}} & \text { Density of solid phase } \\ \rho_{1} & \text { Density of liquid phase }\end{array}$

\section{INTRODUCTION}

Kynch (1952) proposed a theory for the sedimentation process only based on the use of the continuity equation, without the need for detailed knowledge of the forces acting on the particles. In developing his theory, the following assumptions were made: (i) the concentration of particles is uniform along the horizontal; (ii) the initial concentration increases toward the bottom of the container; (iii) the speed of solids tends to zero as the density increases; (iv) the particle fall speed on sedimentation is determined only by the local concentration of the particles; (v) the effects of the wall can be ignored; (vi) the particles have the same size and shape. The theory of Kynch (1952) assumes the existence of an upper interface of sedimentation, and the change of density of solids in suspension propagates as waves from the bottom of the container to this interface. Knowledge of sedimentation interface, along with the initial concentration of the particles is enough to determine the variation of sedimentation of solids.

In the oil well drilling process, fluids are continuously circulated to clean the wellbore, to exert hydrostatic pressure, and to stabilize the wellbore walls (Bourgoyne et al., 1991). The settling of barite or any other weighting material causes undesirable fluctuations in the density and viscosity of drilling fluids. Several problems, such as stuck pipe, difficulties in pressure control, and loss of circulation are caused by barite sag (Omland, 2009). However, it is not yet well known how these and other drilling problems sometimes encountered can be caused by the barite sag. Although an informal poll of major operators confirmed sag is a widespread occurrence, lack of documentation in the literature indicates sag has been underestimated as a contributor to these problems (Hanson et al., 1990). To perform adequately these functions, some physical parameters of the drilling fluids, such as apparent viscosity and density, must be controlled. To achieve the required specific weight, high density solids are added to the drilling fluids (Nguyen et al., 2009). Saasen et al. (1995) studied the barite sag under static and dynamic conditions and found that the viscoelastic properties are related to gel formation which needs to be sufficient to keep barite in suspension. As claimed by Bern et al. (1996), the barite sag produces a significant variation in mud density, caused by the settlement of barite or other weight material. So, in this sense, the mitigation of barite sag is one of the major challenges during the drilling and completion operations (Omland, 2009). Though much work has been done to avoid the consequences imposed by the solid sedimentation, there are no satisfactory solutions, and the phenomenon is still difficult to predict (Nguyen et al., 2009).

According to Crowe and Michaelides (2006), the dispersed solid-liquid two phase flow can be modeled in different ways: using a discrete approach (Lagrangian) or a continuum approach (Eulerian). According to Nguyen (2009), one advantage of the continuum approach is that it provides the theoretical structure by which models can be extended to high concentrations.

Nunziato (1983) used the continuum approach to analyze and solve the flow of fluid with particles. This approach was based on two main assumptions: (i) each phase behaves as a single material, except when it is interacting with the other phase, and (ii) the equation of motion for the mixture takes the same form of the equation for a single phase and it results from summing the equations of motion of each phase of the mixture.

Dong et al. $(2003,2009)$ studied the formation and growth of the particles cake in sedimentation and filtration processes. These authors used the Discrete Elements Technique (DEM) coupled to Computational Fluid Dynamics (CFD) models. The methodology was effective in predicting the properties of cakes formed in filtration and sedimentation processes. Despite its advantages, the DEM based models have high computational cost, which makes this approach unavailable for systems applications with large number of particles, such as particulate systems in drilling fluids.

Hashemian Adariani (2012) investigated barite sag in the annulus under flow conditions, both experimentally and numerically. This seminal work was extended, and Hashemian Adariani et al. (2014a) described the results of the simulation of the barite sag in annular flow using a method called "particle-elimination technique", where the falling and axial velocities were estimated to predict their traveling paths. These authors reported that the highest sag occurs at low annular velocities, low rotational speeds, and high inclination angles. In another work, Hashemian Adariani et al. (2014b) reported the results of an experimental and numerical work concerning barite 
sag in the annulus on a large flow loop to investigate the effects of major drilling parameters. Results of the tests indicated that the highest sag occurs at low annular velocities and rotational speed and, also, at high inclination angles. It was observed that at inclination angles less than $60^{\circ}$, for any annular velocity, barite sag is not significant.

In the present work, a study on the modeling of barite sag in drilling fluids was performed. The emphasis of this study was to evaluate the feasibility of using a simplified two-phase model based on conservation equations to describe the sedimentation of particulate material in drilling fluids. To demonstrate the use of this simplified model as a first approach to model the barite sag, it was evaluated in three different case studies, where the transport and the sedimentation of solid particles in a carrying fluid were simulated. The simulation results included a two-dimensional flow of liquid in the absence of particles; the axial flow of fluid and particles to investigate the existence of the slip velocity; and the one-dimensional particle settling in drilling fluids. The parametric sensitivity of the model was also evaluated for the sedimentation case study, and the simulations were compared to experimental sedimentation results. The system of Partial Differential Equations (PDE) used to model this system was solved by the Method Of Lines (MOL), were the spatial derivatives were discretized by the finite differences method and the time derivative was numerically integrated with the Livermore Solver for Ordinary Differential Equations (LSODE) solver for Ordinary Differential Equations (ODE).

In order to evaluate experimentally the barite sag, sedimentation experiments were conducted according to the graduated cylinder methodology. The experimental results were used to estimate the parameters of the proposed model related to the solid-solid force interaction due to solid particles and the contribution of the pressure gradient. The simulation results showed good agreement with experimental data.

\section{MATERIALS AND METHODS}

\subsection{Modeling Overview of the Base Case}

In this work, the continuum approach was used to model the system illustrated in Figure 1 (Nguyen, 2009). The system was studied in transient conditions in order to evaluate its dynamic behavior.

The process modeling is presented below, were the continuity equation was used for model the solid phase:

$$
\frac{\partial\left(c \rho_{\mathrm{s}}\right)}{\partial t}+\nabla\left(c \rho_{\mathrm{s}} \overrightarrow{\mathrm{s}}_{\mathrm{s}}\right)=0
$$

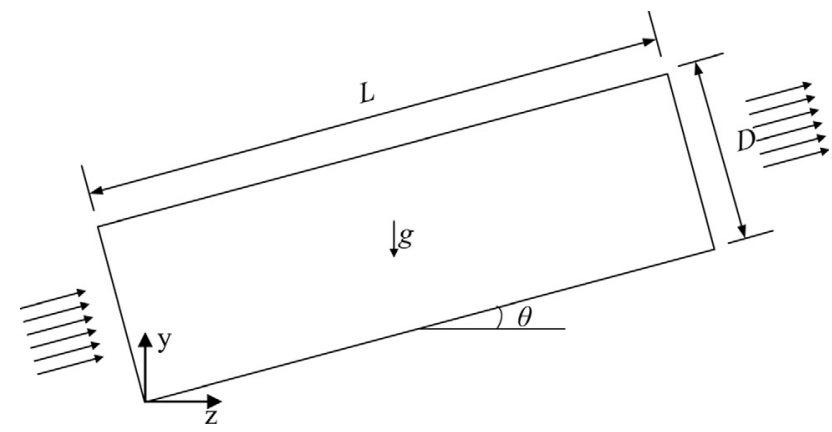

Figure 1

Schematic of the studied system.

For the liquid phase, the continuity equation is given by:

$$
\frac{\partial\left[(1-c) \rho_{1}\right]}{\partial t}+\nabla\left[(1-c) \rho_{1} \vec{v}_{1}\right]=0
$$

Based on the Eulerian approach, Shook and Roco (1991) proposed the following equations for the solid and liquid phases, respectively:

$$
\begin{aligned}
\rho_{\mathrm{s}} \frac{\partial\left(c \overrightarrow{\mathrm{v}}_{\mathrm{s}}\right)}{\partial t}=-\nabla(c P) & +c \rho_{\mathrm{s}} \vec{g}+c\left(\overrightarrow{f_{\mathrm{sl}}}+\overrightarrow{f_{\mathrm{ss}}}+\overrightarrow{f_{\mathrm{sw}}}\right) \\
\rho_{1} \frac{\partial\left[(1-c) \vec{v}_{\mathrm{l}}\right]}{\partial t}= & -\nabla[(1-c) P]+(1-c) \rho_{\mathrm{l}} \vec{g} \\
& +(1-c)\left(\overrightarrow{f_{\mathrm{ls}}}+\overrightarrow{f_{\mathrm{ll}}}+\overrightarrow{f_{\mathrm{lw}}}\right)
\end{aligned}
$$

The interaction forces were modeled by wellestablished literature correlations, such as the Stokes drag law and the Richardson and Zaki's correlation for hindered settling. The constitutive equations used are presented in Equations (12)-(17).

In order to simplify the model, the following considerations were adopted:

- two-dimensional, isothermal and laminar flow;

- the base fluid is Newtonian;

- the inclination angle is equal to zero;

- the pressure profile in axial direction is linear and constant;

- the wall effects are neglected.

\subsection{Case Studies}

In this work, three case studies were proposed to evaluate accuracy of the model in simple flow conditions. In the first case study, the two-dimensional flow of liquid in the absence of particles was simulated, that is, $c=0$. The second case study involved the simulation of axial flow of fluid and particles in order to investigate the presence of slip velocity. 
The third case study focused on the one-directional (no axial flow) particle settling. Further details of the case studies will be given below.

The model of the process, composed of a system of PDE, was solved by the MOL, where the spatial derivatives were discretized by the finite differences method and the time derivative was numerically integrated with the LSODE solver for ODE.

\subsubsection{Two-Dimensional Flow of Liquid in the Absence of Particles}

In this case study, Equations (2) and (4) were used setting $c=0$. Writing the equations in scalar form, the model reduces to:

$$
\begin{gathered}
\frac{\partial v_{\mathrm{l} y}}{\partial y}+\frac{\partial v_{\mathrm{l} z}}{\partial z}=0 \\
\frac{\partial v_{\mathrm{lz}}}{\partial t}=\frac{1}{\rho_{1}}\left[-\frac{\partial P}{\partial z}+\mu_{1}\left(\frac{\partial^{2} v_{\mathrm{l} z}}{\partial y^{2}}+\frac{\partial^{2} v_{\mathrm{l} z}}{\partial z^{2}}\right)\right]-v_{\mathrm{l} y} \frac{\partial v_{\mathrm{l} z}}{\partial y}-v_{\mathrm{l} z} \frac{\partial v_{\mathrm{l} z}}{\partial z} \\
\frac{\partial v_{\mathrm{l} y}}{\partial t}=\frac{1}{\rho_{1}}\left[-\frac{\partial P}{\partial y}+\mu_{1}\left(\frac{\partial^{2} v_{\mathrm{l} y}}{\partial y^{2}}+\frac{\partial^{2} v_{\mathrm{l} y}}{\partial z^{2}}\right)+\rho_{1} g\right] \\
-v_{\mathrm{l} y} \frac{\partial v_{\mathrm{l} y}}{\partial y}-v_{\mathrm{l} z} \frac{\partial v_{\mathrm{l} y}}{\partial z}
\end{gathered}
$$

The initial and boundary conditions used for this case were:

$$
\begin{aligned}
& \left\{\begin{array}{cc}
y=0: v=0 ; & \forall t \\
y=D: v=0 ; & \forall t \\
z=0: v_{\mathrm{l} z}=v_{z 0}, v_{\mathrm{l} y}=0 ; & \forall t \\
z=L: \frac{\partial v}{\partial z}=0 ; & \forall t
\end{array}\right.
\end{aligned}
$$

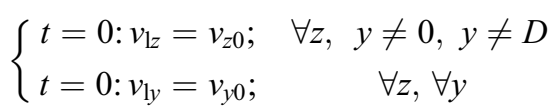

The input data used in this simulation are presented in Table 1.

\subsubsection{Axial Flow of Fluid and Particles}

In this case study, only the $z$-component of Equations (3) and (4) were used. Thus, the model reduces to:

$$
\frac{\partial v_{\mathrm{s} z}}{\partial t}=-\frac{1}{\rho_{\mathrm{s}}}\left(c \frac{\partial P}{\partial z}+P \frac{\partial c}{\partial z}\right)+\frac{1}{\rho_{\mathrm{s}}}\left(f_{\mathrm{sl}}^{z}+f_{\mathrm{ss}}^{z}\right)
$$

TABLE 1

Parameters used in the first case study.

\begin{tabular}{c|c|c|c}
\hline Variable & Symbol & Value & Units \\
\hline Height & $D$ & 0.1016 & $\mathrm{~m}$ \\
\hline Length & $L$ & 10.67 & $\mathrm{~m}$ \\
\hline Gravity & $g$ & 9.81 & $\mathrm{~ms}^{-2}$ \\
\hline Pressure drop in $z$ & $\Delta P_{z}$ & 200.00 & $\mathrm{~Pa}$ \\
\hline Pressure drop in $y$ & $\Delta P_{y}$ & $\rho g$ & $\mathrm{~Pa}$ \\
\hline Initial velocity & $v_{z 0}$ & 0.1557 & $\mathrm{~ms}^{-1}$ \\
\hline
\end{tabular}

$$
\frac{\partial v_{\mathrm{l} z}}{\partial t}=-\frac{1}{\rho_{1}(1-c)}\left((1-c) \frac{\partial P}{\partial z}-P \frac{\partial c}{\partial z}\right)+\frac{1}{\rho_{1}}\left(f_{\mathrm{ls}}^{z}+f_{11}^{z}\right)
$$

To model the interaction force between solids and liquid, Equation (12) was used.

$$
f_{\mathrm{sl}}^{z}=\frac{3 C_{D z} \rho_{\mathrm{l}}\left(v_{\mathrm{l} z}-v_{\mathrm{s} z}\right)}{4 d_{\mathrm{s}}(1-c)^{1.7}}\left(v_{\mathrm{l} z}-v_{\mathrm{s} z}\right)
$$

where

$$
C_{D_{\mathrm{S}}}=\frac{24}{R e_{\mathrm{Sz}}}
$$

and

$$
\operatorname{Re}_{\mathrm{s} z}=\frac{d_{\mathrm{s}}(1-c)\left(v_{\mathrm{lz}}-v_{\mathrm{sz}}\right) \rho_{1}}{\mu_{1}}
$$

To quantify the liquid-solid force, the continuum approach was used. Once this methodology considers that all momentum lost by a phase, is gained by the other phase, Equation (15) was used to accounts for this calculation.

$$
c f_{\mathrm{sl}}^{z}+(1-c) f_{\mathrm{ls}}^{z}=0 \quad \text { or } \quad f_{\mathrm{ls}}^{z}=-\frac{c}{1-c} f_{\mathrm{sl}}^{z}
$$

The solid-solid and liquid-liquid forces were modeled in a similar way using the shear force, according to Equations (16) and (17), respectively.

$$
\begin{gathered}
c f_{\mathrm{ss}}^{z}=-\mu_{\mathrm{s}} \nabla\left(c \frac{\partial v_{\mathrm{s} z}}{\partial y}\right)=-\mu_{\mathrm{s}} \frac{\partial}{\partial y}\left(c \frac{\partial v_{\mathrm{s} z}}{\partial y}\right) \\
(1-c) f_{11}^{z}=-\mu_{\mathrm{l}} \nabla\left[(1-c) \frac{\partial v_{\mathrm{l} z}}{\partial y}\right]=-\mu_{\mathrm{l}} \frac{\partial}{\partial y}\left[(1-c) \frac{\partial v_{\mathrm{l} z}}{\partial y}\right]
\end{gathered}
$$


The initial and boundary conditions used for this case were:

$$
\begin{gathered}
y=0: v_{\mathrm{l} z}=v_{\mathrm{s} z}=0 ; \forall t \\
y=D: v_{\mathrm{l} z}=v_{\mathrm{s} z}=0 ; \forall t \\
t=0: v_{\mathrm{l} z}=v_{z 0} ; \forall y ; \quad y \neq 0 ; \quad y \neq D \\
t=0: v_{\mathrm{s} z}=0 ; \forall y
\end{gathered}
$$

\subsubsection{One-Directional (No Axial Flow) Particle Settling}

This case study used the model to simulate the batch sedimentation process. Particles settle down vertically, without axial flow, as shown in Figure 2. In this case study, the Equation (1) and the $y$-component of Equation (3) were used, so the model was reduced to:

$$
\begin{gathered}
\frac{\partial c}{\partial t}=-c \frac{\partial v_{\mathrm{s} y}}{\partial y}-v_{\mathrm{s} y} \frac{\partial c}{\partial y} \\
\frac{\partial v_{\mathrm{s} y}}{\partial t}=g-\frac{1}{\rho_{\mathrm{s}}} \frac{\partial P}{\partial y}+\frac{1}{\rho_{\mathrm{s}}}\left(f_{\mathrm{sl}}^{y}+f_{\mathrm{ss}}^{y}\right)
\end{gathered}
$$

The pressure gradient was considered balanced with the weight of suspension, proportional to an empirical coefficient, $b$, according to the Equation (24).

$$
\frac{\partial P}{\partial y}=-b\left(c \rho_{\mathrm{s}}+(1-c) \rho_{1}\right) g
$$

The coefficient $b$ in Equation (25) was adjusted with experimental data from multiples barite settling tests for three differences concentration of solids at $6.7 \%, 12 \%$, and $20 \%$, using the graduated cylinder methodology.

$$
b=\frac{c_{\max }}{6 c_{0}\left(c_{0}^{2}-0.15 c_{0}+0.006\right)}
$$

The initial and boundary conditions used for this case were:

$$
\begin{gathered}
y=0: v_{\mathrm{s} y}=v_{\infty} ; \forall t \\
y=L: v_{\mathrm{s} y}=0 ; \forall t \\
t=0: v_{\mathrm{s} y}=v_{\infty} ; \forall y \\
t=0: c=c_{0} ; \forall y
\end{gathered}
$$

\subsection{Experimental Set-Up}

To evaluate the model, settling experiments using the graduated cylinder methodology were conducted. This

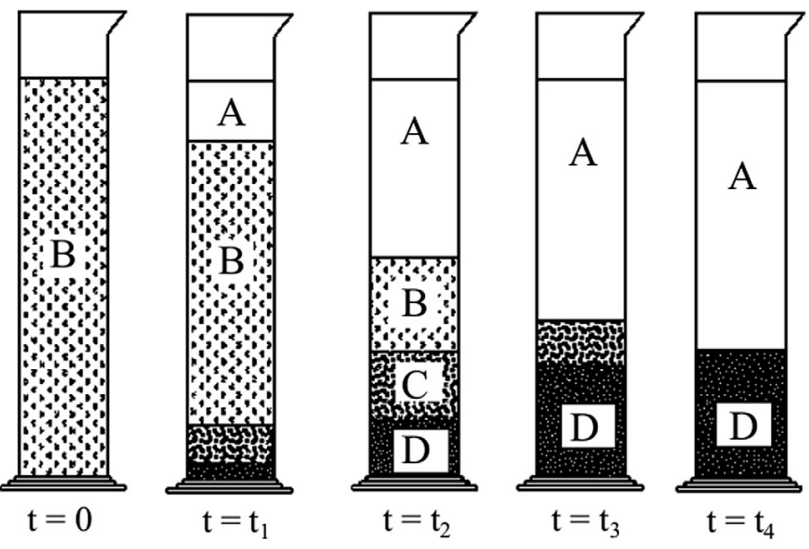

Figure 2

Illustration of the fall of the upper interface during the batch settling of a suspension.

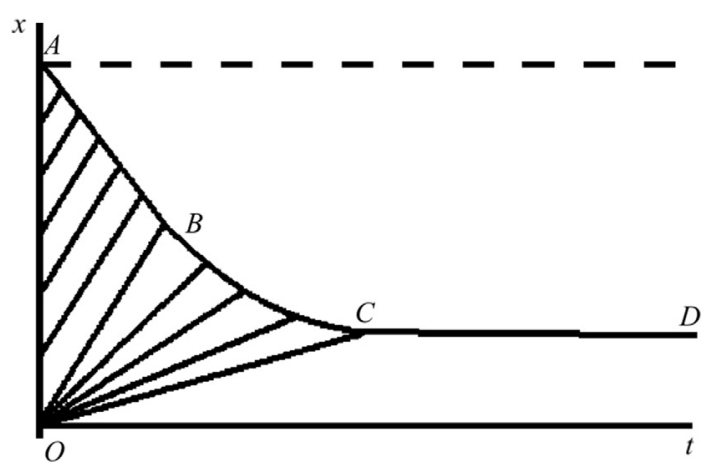

Figure 3

Fall of surface of dispersion, showing lines of density propagation when initial density is uniform (Kynch, 1952).

methodology consists of a batch sedimentation test in which the fall of the upper interface of the suspension is monitored (Fig. 2).

The graduated cylinder methodology can be related to the theory of Kynch (1952) by considering Figure 3, where it is possible to notice the evolution of the batch sedimentation process with time. The change of position of the upper interface over time is represented by the line A-D. The sedimentation of a suspension initially generates four homogeneous sedimentation areas: a clear zone (A), a zone of constant initial concentration (B), a transition zone with varying concentrations (C), and a compression zone (D).

The experimental tests were conducted with suspensions with different amounts of barite in water. This experimental system of barite suspensions in water was used in order to better scan the interface decay. The suspensions were stirred for $15 \mathrm{~min}$ in a $1.5-\mathrm{HP}$ mixer and the dispensed into a 1-L graduated cylinder. After that, the timer was triggered and 
TABLE 2

Physicochemical properties of the liquid systems.

\begin{tabular}{c|c|c|c|c}
\hline Component & Density $\left(\mathrm{kg} \mathrm{m}^{-3}\right)$ & Viscosity $(\mathrm{cP})$ & Mean diameter $(\mu \mathrm{m})$ & Volumetric fraction $(\% \mathrm{v} / \mathrm{v})$ \\
\hline Mineral oil & 850.60 & 62.00 & - & - \\
\hline Water & 997 & 1 & - & - \\
\hline Xantham gum $0.4 \% \mathrm{w} / \mathrm{v}$ & 998.4 & 580 & 30.0 & - \\
\hline Barite & 3920 & - & $6.7-20.0$ \\
\hline
\end{tabular}

the fall of the upper interface of the suspension was monitored (Kynch, 1952; Massarani, 2002).

The results of these tests were used to adjust the correlations used in the model, as well as to evaluate the accuracy of the predictions of the mathematical model of the process. Besides, the model was also used for the simulation of a mineral oil and a xantham gum water-based fluid, whose properties are presented in Table 2 .

\section{RESULTS AND DISCUSSION}

\subsection{Two-Dimensional Flow of Liquid in the Absence of Particles}

The results of the simulation for the two-dimensional steadystate flow of three pure liquid systems are presented in Figure 4. The fluids used were: pure water, a mineral oil and a xantham gum suspension with $0.4 \% \mathrm{w} / \mathrm{v}$ in water. In Figure 4, the formation of the parabolic velocity profile can be observed, which is the classic behavior for this flow configuration. Near the entrance, the plug flow behavior can be observed, which corresponds to the feed condition used in these simulations.

The result for $z=10.67 \mathrm{~m}$ was compared to the classic parabolic profile given by (Bird et al., 2007).

$$
v_{\mathrm{lz} \infty}=\frac{\Delta P}{2 \mu L}\left(y^{2}-D y\right)
$$

The steady-state velocity profiles at $z=10.67 \mathrm{~m}$ are presented in Figure 5.

According to results shown in Figure 5, it can be confirmed that the numeric solutions provided by the model used in this work are close to the exact solution, thus ratifying the proposed modeling approach.

\subsection{Axial Flow of Fluid and Particles}

In this case study, the velocity of the particles was set to zero at the beginning of the simulation. The goal of this study was to analyze the necessary time for the solids reach $99 \%$ of the liquid velocity in order to verify the existence or not of the slip velocity.

The simulation was carried out for suspensions with $6.7 \%$ $\mathrm{v} / \mathrm{v}$ of barite particles $\left(\rho=3920 \mathrm{~kg} \mathrm{~m}^{-3}\right.$ and $\left.d=21 \mu \mathrm{m}\right)$ in mineral oil $\left(\mu=62 \mathrm{cP}\right.$ and $\left.\rho=856.6 \mathrm{~kg} \mathrm{~m}^{-3}\right)$. The results for this case study are shown in Figure 6 , where it was observed the slip velocity close to $1.0 \times 10^{-8} \mathrm{~ms}^{-1}$, and the necessary time for the solid particles reach $99 \%$ of this liquid velocity was $6.7 \times 10^{-6} \mathrm{~s}$. This is an indication that the assumption of considering an average speed in $z$-direction can be used, since this hypothesis will spend less computational resources.

\subsection{One-Directional (No Axial Flow) Particle Settling}

In this section, the evaluation of the concentration profiles of barite as a function of height and time, as well as the influence of particle size, liquid viscosity, and initial solid concentration of the suspension were analyzed in order to understand how these parameters influence the process behavior.

\subsubsection{Evaluation of the Concentration Profiles and Estimation of the Clarification Front}

In these simulated profiles, the fall of the upper limit of the suspension (the clarification front) is presented for different sedimentation times, as well as the correspondent formation of the bed of barite particles at the bottom of the device. The model was also able to predict the presence of the three distinct zones: a clarified liquid zone, the settling zone, and the particles bed zone.

The concentration profiles of barite as a function of height and time for the simulation of the barite sag in water are presented in Figure $7\left(c_{0}=0.067\right)$ and in Figure 9 $\left(c_{0}=0.12\right)$.

The height of the clarification front (for $c_{0}=0.067$ ) calculated by the proposed model was compared to the 


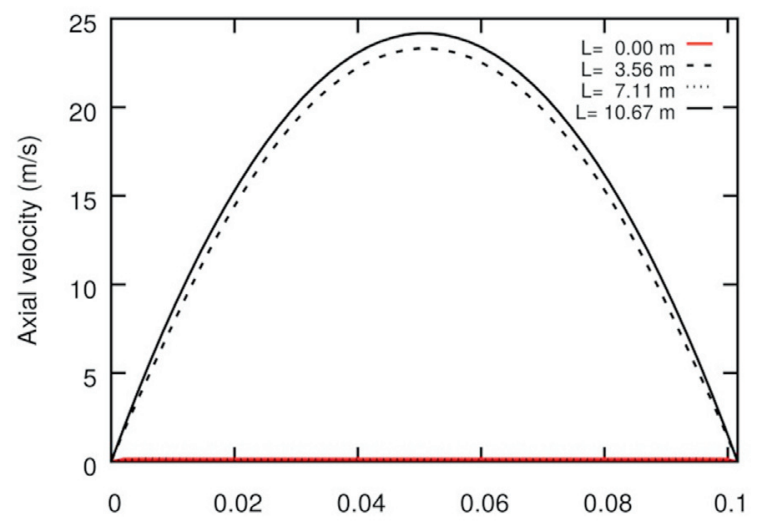

a)

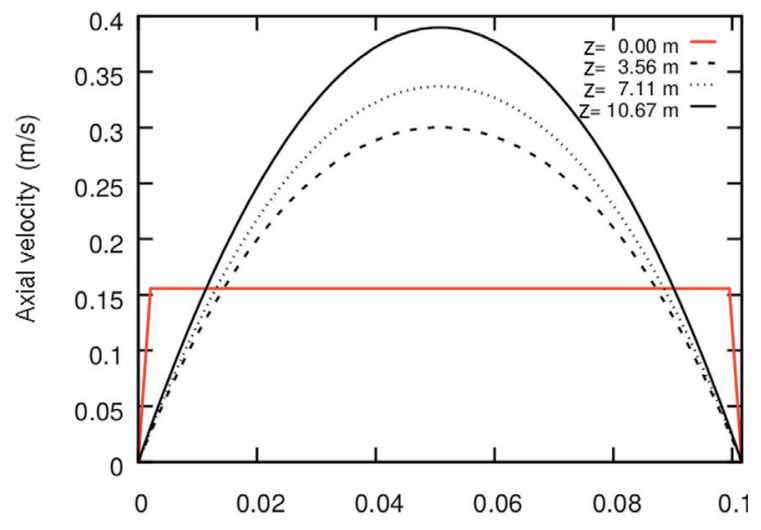

b)

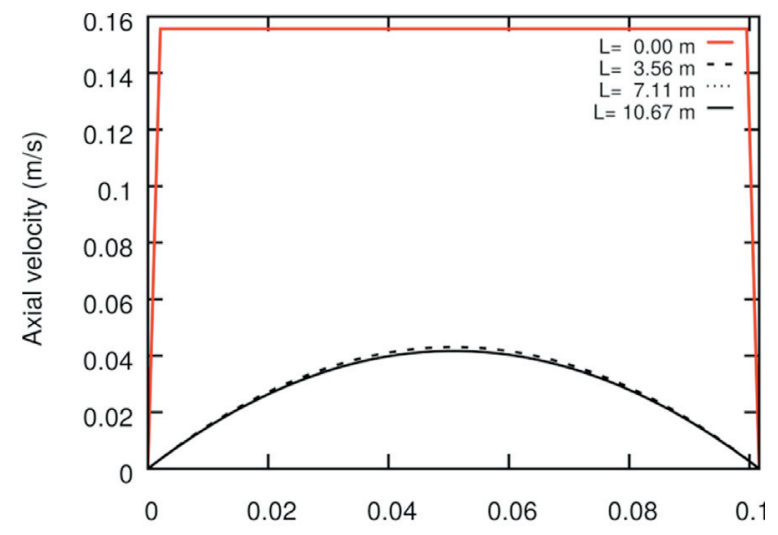

c)

Pipe diameter $(m)$

Figure 4

Velocity profiles as a function of the height $(y)$ for different positions (z). a) Water at $t=10205.5 \mathrm{~s}$; b) Mineral oil at $t=130.7 \mathrm{~s} ; \mathrm{c})$ Xantham gum $0.4 \% \mathrm{w} / \mathrm{v}$ at $t=22.1 \mathrm{~s}$.

experimental results and, as can be observed in Figure 8, the results obtained from the model showed a good agreement to the experimental data.

The height of the clarification front, for $c_{0}=0.12$, calculated by the proposed model was compared to the

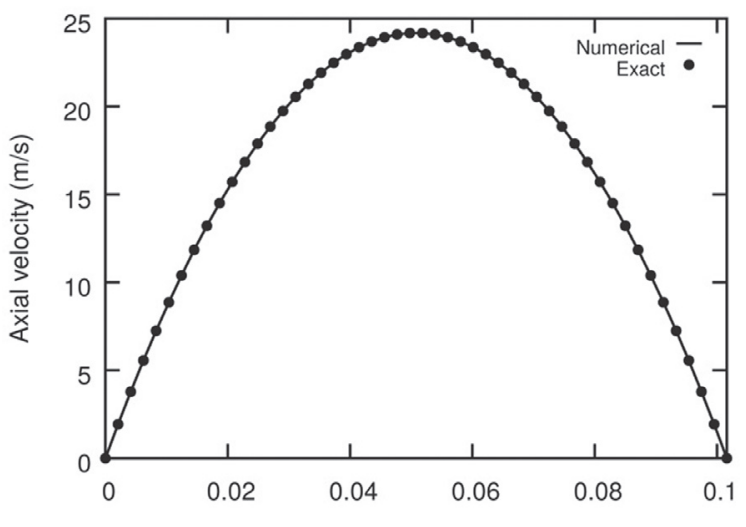

a)

Pipe diameter $(\mathrm{m})$

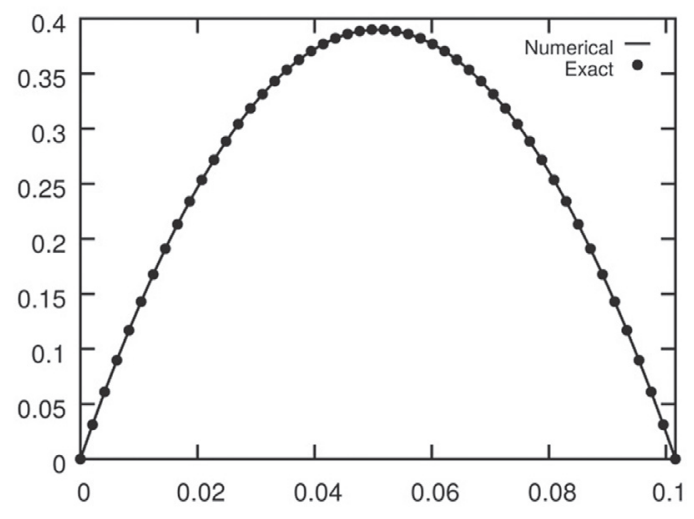

b)

Pipe diameter $(\mathrm{m})$

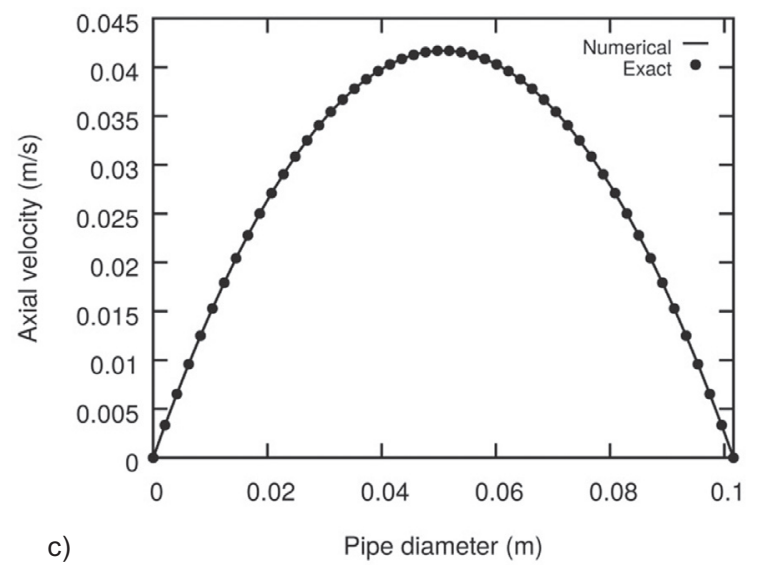

Figure 5

Velocity profiles as a function of the height $(y)$ : exact $(-)$ and numerical () solutions. a) Water at $t=10205.5 \mathrm{~s}$; b) Mineral oil at $t=130.7 \mathrm{~s}$; c) Xantham gum $0.4 \% \mathrm{w} / \mathrm{v}$ at $t=22.1 \mathrm{~s}$.

experimental results and again, as can be observed in Figure 10, the results obtained from the model showed a good agreement to the experimental data.

In Sections 2.3.2-2.3.4, the influence of particle size, liquid viscosity, and initial solid concentration of the 


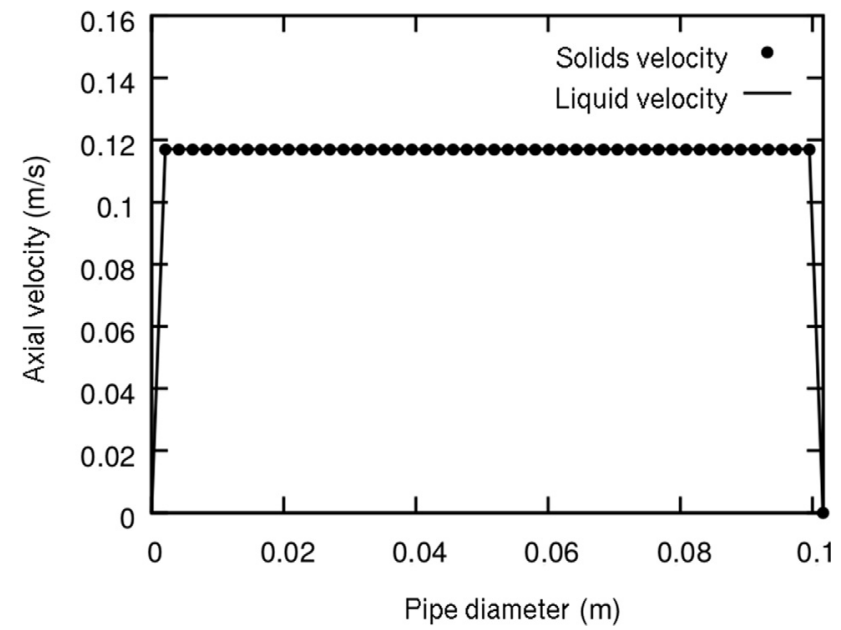

Figure 6

Velocity profiles of liquid and solids flows at $t=6.7 \times 10^{-6} \mathrm{~s}$.

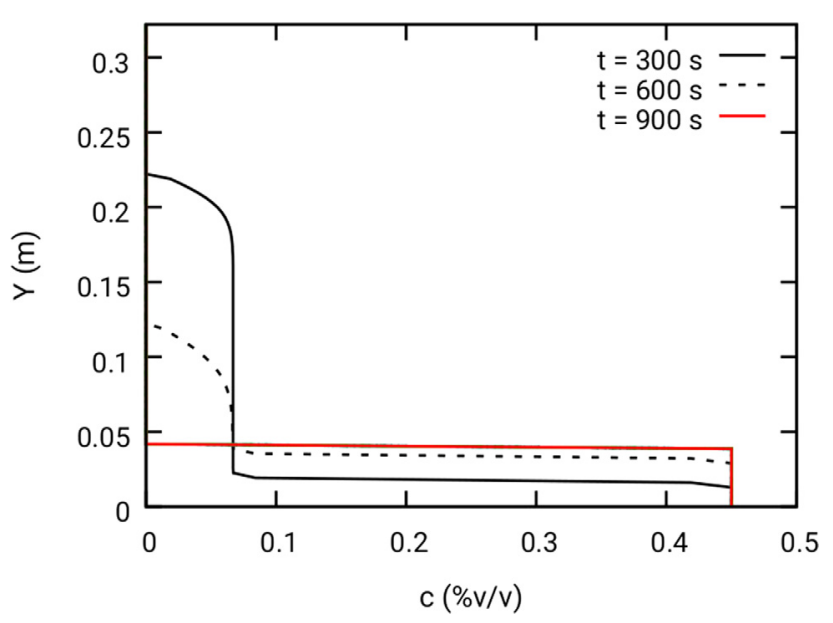

Figure 7

Concentration profiles of barite $\left(c_{0}=6.7 \%\right)$ as a function of height and time.

suspension were analyzed. Simulations conditions were shown in Table 3.

\subsubsection{Influence of Particle Size}

This study was carried out using three different particle sizes $(10,30$, and $60 \mu \mathrm{m})$, three liquids with different viscosities (1, 3, and $5 \mathrm{cP}$ ), and three initial solid concentrations $(6.7,12$, and $20 \%)$.

Predictions of the influence of the particle size, keeping the liquid viscosity and the initial solid concentration fixed as $1 \mathrm{cP}$ and $6.7 \%$, respectively, are shown in Figure 11.

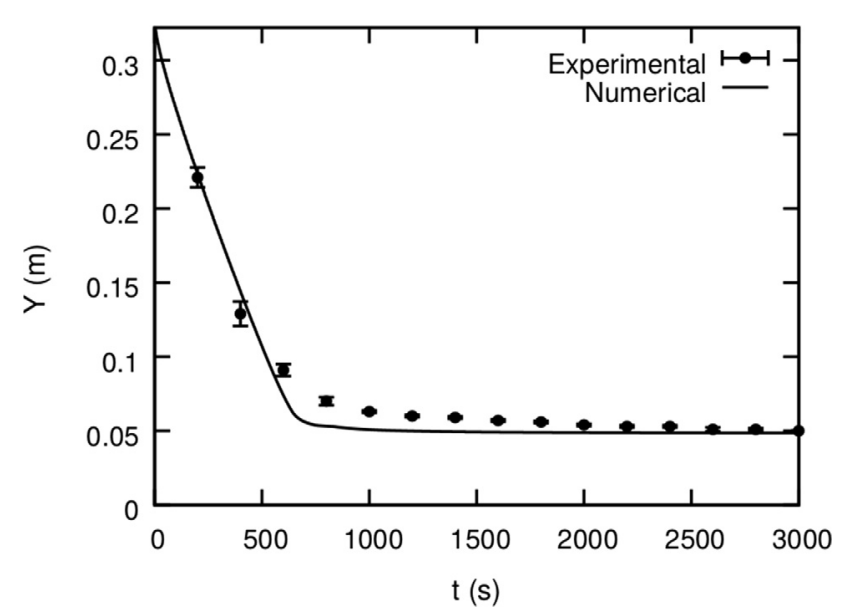

Figure 8

Height of the interface between the clarified liquid and settling zones (clarification front) as a function of time: predicted versus experimental data for $c_{0}=6.7 \%$.

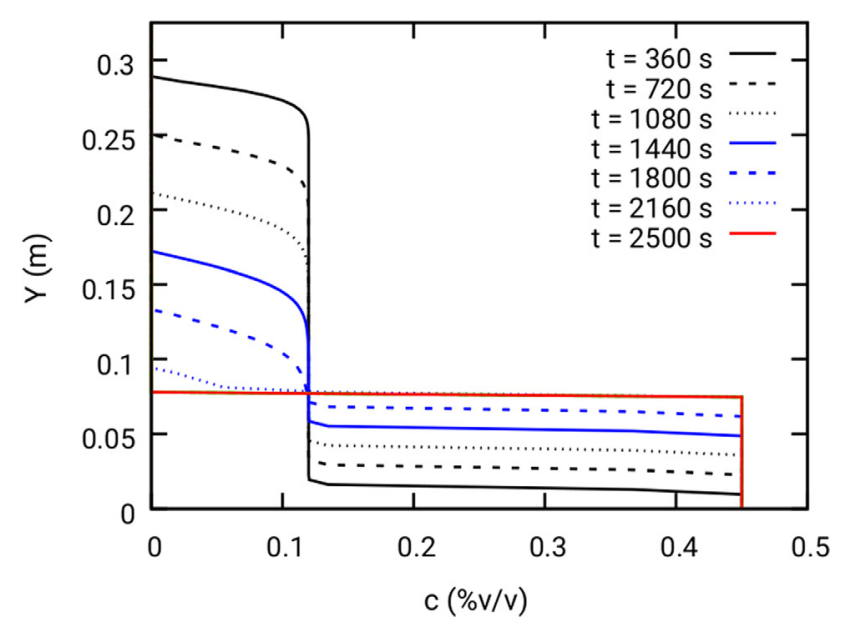

Figure 9

Concentration profiles of barite $\left(c_{0}=12 \%\right)$ as a function of height and time.

It can be observed that as the particle size increases, the settling speed increases too. According to previous work (Brennen, 2005), it is known that as particle diameter approaches to zero the system tends to behave like a single phase system.

\subsubsection{Influence of Viscosity}

Simulations using arbitrary fluids with viscosities with 1,3 , and $5 \mathrm{cP}$ were conducted, fixing the particle diameter in $30 \mu \mathrm{m}$ and the initial solid concentration in $6.7 \%$. The results for these simulations are presented in Figure 12, 


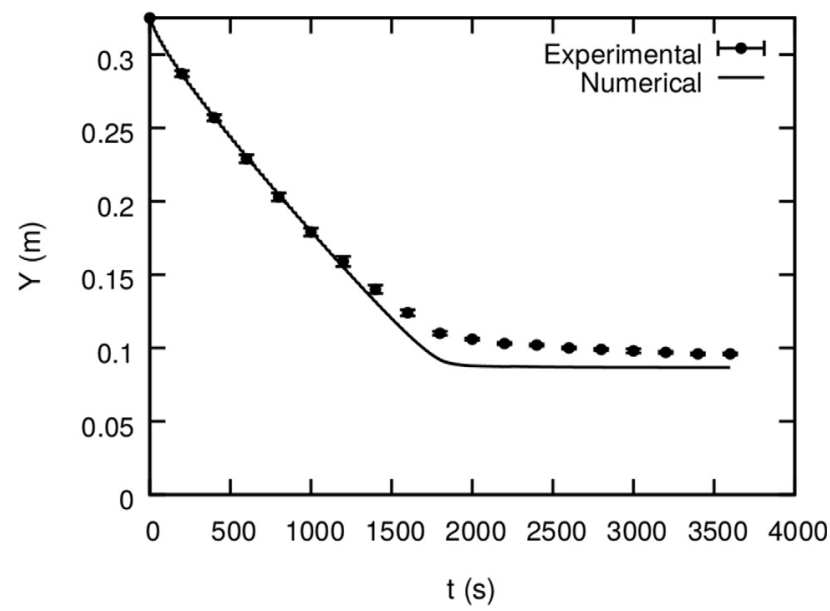

Figure 10

Height of the interface between the clarified liquid and settling zones (clarification front) as a function of time: predicted versus experimental data for $c_{0}=12 \%$.

TABLE 3

Simulations conditions used in Sections 2.3.2-2.3.4.

\begin{tabular}{c|c|c}
\hline Particle size & Viscosity & Solid concentration \\
\hline$d_{\mathrm{p}}=10,30$, and $60 \mu \mathrm{m}$ & $d_{\mathrm{p}}=30 \mu \mathrm{m}$ & $d_{\mathrm{p}}=30 \mu \mathrm{m}$ \\
\hline$\mu=1 \mathrm{cP}$ & $\mu=1,3$, and $5 \mathrm{cP}$ & $\mu=1 \mathrm{cP}$ \\
\hline$c_{0}=6.7 \%$ & $c_{0}=6.7 \%$ & $c_{0}=6.7,12$, and $20 \%$ \\
\hline
\end{tabular}

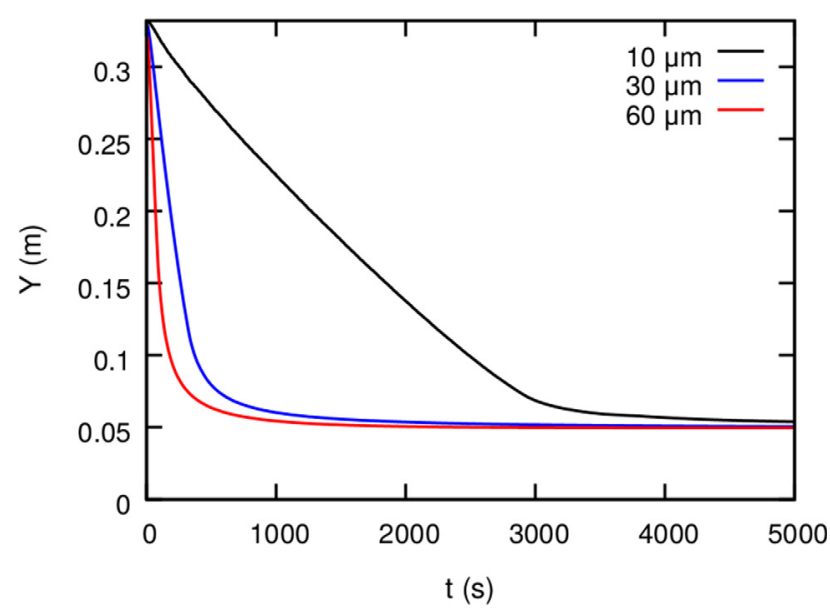

Figure 11

Model predictions for the height of the interface between the clarified liquid and settling zones (clarification front) as a function of time: liquid viscosity of $1 \mathrm{cP}$ and initial solid concentration $6.7 \%$.

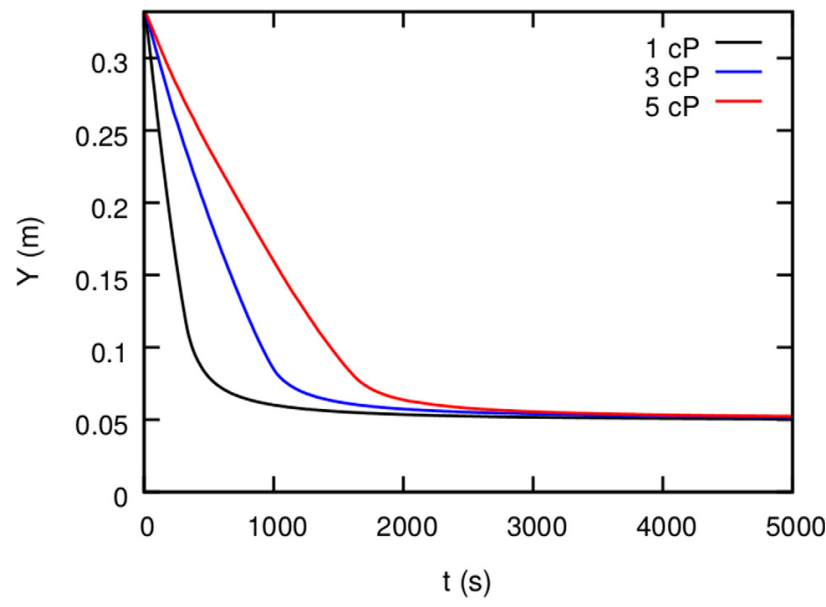

Figure 12

Model predictions for the height of the interface between the clarified liquid and settling zones (clarification front) as a function of time: particle diameter of $30 \mu \mathrm{m}$ and initial solid concentration $6.7 \%$.

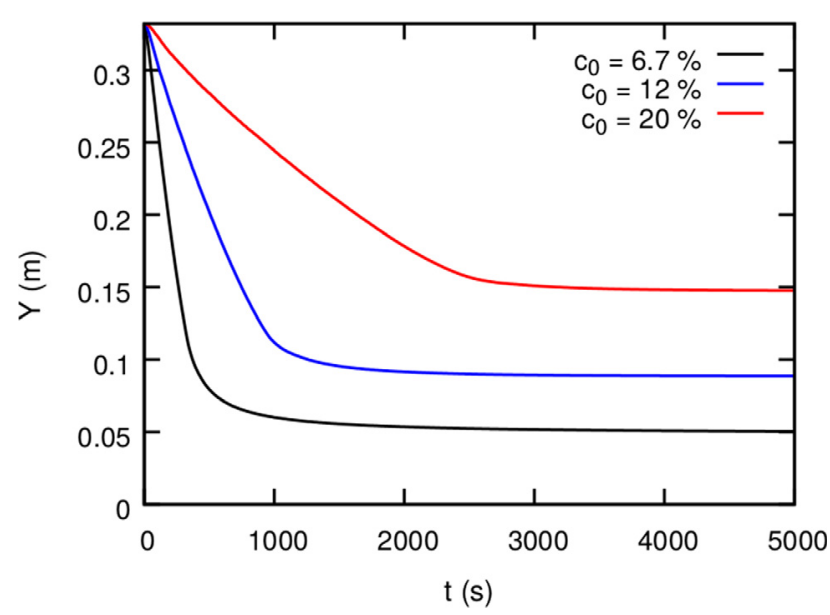

Figure 13

Model predictions for the height of the interface between the clarified liquid and settling zones (clarification front) as a function of time: particle diameter of $30 \mu \mathrm{m}$ and fluid viscosity of $1 \mathrm{cP}$.

where it can be observed that as viscosity increases, the settling speed decreases. This behavior may be explained considering that the drag force increases with the viscosity of the liquid.

\subsubsection{Influence of Solid Concentration}

Another simulation study was conducted considering the effect of the initial concentrations of the solid phase. The initial solid contents investigated were $6.7,12$, and $20 \%$, 
while the particle diameter and fluid viscosity were fixed in $30 \mu \mathrm{m}$ and $1 \mathrm{cP}$, respectively. The simulation results for three different initial solids concentrations are presented in Figure 13, where can be observed that as solids concentration increases, the settling speed decreases. This behavior was already observed experimentally and is well-posed in literature, which is known as hindered settling (Massarani, 2002).

\section{CONCLUSION}

The aim of this study was to describe the barite settling using a simplified model based on the mass and momentum conservation equations. This modeling approach used a constitutive equation obtained from the literature to model the solid-fluid and fluid-fluid interaction forces as well as an empirical correlation to correct the contribution of the pressure gradient in the barite sag. The ensemble of those equations was used to evaluate the barite sag in oil and water based drilling fluids. The set of equations was able to predict the two-dimensional fluid flow, the particle drag by a fluid, and the batch settling process. The model predictions were close to classical analytical solutions and to experimental data, except for the compression zone, since the proposed model does not take into account this region.

Simulations were carried out to evaluate the model behavior in three different settling conditions by varying particle size, viscosity, and solid concentration. Using particles sizes ranging from 10-60 $\mu \mathrm{m}$, the proposed model predicted an increasing in the settling rate as the particle diameter increases. Varying the viscosities from 1-5 $\mathrm{cP}$, it was found that an increase in liquid viscosity promoted a decreasing in the settling speed. Finally, when the initial solids concentrations varied from $6.7-20 \%$, the model was also able to predict that an increase in the solid concentration reduces the settling rate, which is known as hindered settling.

According to the results presented in this work, the model predictions showed good agreement with experimental data. Therefore, despite to the simplicity of the proposed model, it could be used as a first approach to the modeling of the barite sag in drilling fluids. Since the model was able to predict the barite sedimentation as well as the formation and the properties of the bed of particles, thus providing a better understanding of these phenomena, this information can help the drilling engineers to predict such problems and act preventively to mitigate them. Moreover, the proposed model can be used to evaluate the influence of the particle size, the liquid viscosity, and the solids concentration on the sedimentation process of particles in drilling fluids.

\section{ACKNOWLEDGMENTS}

Authors gratefully acknowledge the financial and technical support provided by CENPES/PETROBRAS, FINEP, CNPq, and CAPES.

\section{REFERENCES}

Bern P.A., Zamora M., Slater K.S., Hearn P.J. (1996) The influence of drilling variables on barite sag, Society of Petroleum Engineers. SPE Annual Technical Conference and Exhibition, Denver, Colorado.

Bird R.B., Stewart W.E., Lightfoot E.N. (2007) Transport phenomena, John Wiley \& Sons, New York.

Bourgoyne A.T., Milheim K.K., Chenevert M.E., Young F.S. (1991) Applied Drilling Engineering, Society of Petroleum Engineers, Richardson, Texas.

Brennen C. (2005) Fundamentals of multiphase flow, Cambridge University Press, Pasadena, California.

Crowe C., Michaelides E. (2006) Multiphase flow handbook, Taylor \& Francis Group, LLC

Dong K., Yang R., Zou R., Yu A., Roach G., Jamieson E. (2003) Simulation of the cake formation and growth in sedimentation and filtration, Third International Conference on CFD in the Minerals and Process Industries, 10-12 December, CSIRO, Melbourne, Australia.

Dong K., Zou R., Yang R., Yu A., Roach G. (2009) DEM simulation of cake formation in sedimentation and filtration, Miner. Eng. 22, 921-930.

Hanson P.M., Trigg T.K., Rachal G., Zamora M. (1990) Investigation of barite sag in weighted drilling fluids in highly deviated wells, Society of Petroleum Engineers. SPE Annual Technical Conference and Exhibition, New Orleans, Louisiana, pp. 223-230.

Hashemian Adariani Y. (2012) Experimental study and modeling of barite sag in annular flow, $P h D$ Dissertation, Petroleum Engineering Department, The University of Tulsa, Tulsa, USA.

Hashemian Adariani Y., Miska S., Yu M., Ozbayoglu E., Takach N., McLaury B. (2014a) Experimental study and modelling of barite sag in annular flow, J. Can. Petrol. Technol. 365-374.

Hashemian Adariani Y., Miska S., Yu M., Ozbayoglu E., Takach N. (2014b) Numerical simulation and experiments of barite sag in horizontal annulus, Am. J. Numer. Anal. 2, 1, 14-19.

Kynch G. (1952) A theory of sedimentation, Trans. Amer. Soc. 48, 166-176.

Massarani G. (2002) Fluid dynamics in particulate systems, E-papers, Rio de Janeiro.

Nguyen T. (2009) Predicting dynamic barite sag in oil based drilling fluids, Drilling Research Projects, The University of Tulsa, Tulsa, USA.

Nguyen T., Miska S., Takach N. (2009) Predicting dynamic barite sag in oil based drilling fluids, SPE Annual Technical Conference and Exhibition, New Orleans, Louisiana.

Nunziato J.W. (1983) A multiphase mixture theory for fluid-particle flows. Theory of Dispersed Multiphase Flow, edited by Meyer R.E., Academic Press, New York. pp. 191-226. 
Omland T. (2009) Particle settling in non-newtonian drilling fluids, PhD Thesis in Petroleum Engineering, University of Stavanger, Stavanger.

Saasen A., Liu D., Marken C.D. (1995) Prediction of barite sag potential of drilling fluids from rheological measurements, Society of Petroleum Engineers. SPE/IADC Drilling Conference, Amsterdam, Netherlands, pp. 663-671.
Shook A., Roco C. (1991) Slurry flow - principles and practice, Butterworth-Heinemann, Boston.

Manuscript submitted in July 2016

Manuscript accepted in May 2017

Published online in September 2017 